\title{
FOUQUET, Gerhard, Bauen für die Stadt. Finanzen, Organisation und Arbeit im kommunalen Baubetrieb des Spätmittelalters
}

Pierre Monnet

\section{OpenEdition}

Journals

Édition électronique

URL : http://journals.openedition.org/ifha/1294

DOI : 10.4000/ifha.1294

ISSN : 2198-8943

Éditeur

IFRA - Institut franco-allemand (sciences historiques et sociales)

Référence électronique

Pierre Monnet, «FOUQUET, Gerhard, Bauen für die Stadt. Finanzen, Organisation und Arbeit im kommunalen Baubetrieb des Spätmittelalters », Revue de l'IFHA [En ligne], Date de recension, mis en ligne le 01 janvier 2000, consulté le 22 septembre 2020. URL : http://journals.openedition.org/ifha/1294 DOI : https://doi.org/10.4000/ifha.1294

Ce document a été généré automatiquement le 22 septembre 2020.

(CIFHA 


\title{
FOUQUET, Gerhard, Bauen für die Stadt. Finanzen, Organisation und Arbeit im kommunalen Baubetrieb des Spätmittelalters
}

\author{
Pierre Monnet
}

\begin{abstract}
À la question de savoir ce que fut la ville médiévale, l'historien ne peut qu'apporter une réponse complexe : une communauté de droits, une organisation sociale particulière, un ensemble de valeurs et d'idéaux... mais assurément aussi des rues, des places, des fontaines, des maisons, des églises et des bâtiments publics. N'est-ce pas d'ailleurs le seul legs directement sensible et visible transmis à nous par la cité médiévale (ce qui ne veut pas dire que cet héritage "matériel » soit plus facile à interpréter) ? Paraissant dans une collection dédiée à l'histoire urbaine et qui a déjà accueilli plusieurs titres consacrés au bâti et à la construction (Antje Sander-Berke, Baustoffversorgung spätmittelalterlicher Städte, 1995 et Gabriele Isenberg, Barbara Solkmann (dir.), Die Befestigung der mittelalterlichen Stadt), le livre de G.F. indique d'emblée par son titre une ambition à la mesure des problématiques actuelles : écrire une histoire politique et sociale de la construction urbaine médiévale (on peut penser en France aux travaux conduits selon cette même approche par Philippe Braunstein, par Philippe Bernardi avec son ouvrage Métiers du bâtiment et techniques de construction à Aix-en-Provence à la fin de l'époque gothique (1400-1550), Aix-en-Provence, 1995 ou bien par Patrick Boucheron avec son étude sur Le pouvoir de bâtir. Urbanisme et politique édilitaire à Milan (XIVe-XVe siècles), Rome, 1998). Car bâtir dans la ville médiévale, ce n'est pas seulement satisfaire à un besoin élémentaire, c'est inscrire dans l'espace une marque de souveraineté, une identité, c'est matérialiser le Bien Commun ou le Bon Gouvernement (voir la célèbre fresque de Lorenzetti), c'est négocier une redéfinition et une répartition des groupes sociaux, c'est témoigner d'une efficacité (y compris et peut-être surtout financière...) sur le terrain qui vaut bien la sempiternelle "discipline sociale » de l'historiographie actuelle.
\end{abstract}


2 Pour le démontrer, l'étude se concentre sur une période charnière qui va de 1440 à 1550 et sur deux exemples, Bâle et Marbourg. Sous cet angle, les deux villes ne se signalent pas seulement par leur admirable situation documentaire (des séries continues de comptes urbains) mais aussi par une organisation politique qui permet de faire le point des ressemblances et des différences : une ville d'Empire importante d'un côté, forte de 8000 à 9000 habitants dans la seconde moitié du XVe s., dirigée par un Conseil oligarchique ; et de l'autre, une ville "territoriale ", c'est-à-dire très marquée par la résidence et la présence princières, incluant dans son périmètre à peine plus de 3000 habitants au XVe s. Naturellement, ces deux villes font l'objet de comparaisons incessantes avec la situation des autres cités allemandes aux XVe et XVIe s. (Colmar, Constance, Erfurt, Francfort-sur-le-Main, Hambourg, Karlsruhe, Lubeck, Münster, Porrentruy, Siegen, Ulm et Zurich).

3 À partir des comptabilités urbaines et des comptes et récits de construction, des ordonnances et décisions du Conseil, des statuts et archives des corps de métier et des registres d'impôt, l'auteur ne se contente pas de construire des tableaux et diagrammes statistiques des salaires, coûts et budgets de construction (il y en a une soixantaine en annexe, tous admirables de méthode et de présentation), mais mène sa recherche entre les deux pôles de la problématique retenue : une "urbanisation intérieure " (à concevoir au sens politique et culturel du terme comme un processus de civilisation par la ville à travers son bâti, ce qui tranche définitivement avec la période industrielle qui forme ici la véritable césure) et une histoire sociale du travail qui interroge les statuts, les dénominations, les contrats, les rapports de travail sur le chantier comme entre les corps de métier, la conscience professionnelle, les relations entre les maitres d'œuvre (Conseil, prince, magistrats spécialisés...) et les exécutants. Une réflexion sur l'institutionnalité d'une telle activité en ville ne laisse pas de côté des thèmes aussi importants que la planification, la pensée de l'espace (qui n'exclut pas le recours intellectuel à l'utopie) ou l'émergence d'une conscience de l'environnement, associée à une pesée des dangers et de leur prévention, analyse conduite à partir du cas exemplaire de la lutte contre les incendies. Construire ne fut pas seulement affaire de possibilité mais aussi de volonté, et une telle optique renvoie à l'organisation d'ensemble et aux choix de chaque micro-société urbaine : avec trois fois plus de population que Marbourg, Bâle a dépensé quinze fois plus pour ses chantiers. Il va sans dire qu'une telle approche et une telle interprétation ne peuvent qu'ouvrir de nouveaux chantiers qui attendent leurs apprentis et leurs maçons. 